\title{
EVALUERING VAN GESINDHEID IN KLINIESE ONDERRIG
}

Referaat gelewer by 'n simposium ter viering van die 25e verjaardag van die graadkursusse in Verpleegkunde aan die Universiteit van Pretoria en in Suid-Afrika.

PROF. A.M. VENTER

Universiteit van Wes-Kaapland

\section{SUMMARY}

The affective dimension of nursing - which involves attitudes, values and interests - is a very important one and should be evaluated in the clinical area where the student nurse deals with the real situation.

Evaluations of the affective dimension are currently often subjective value judgements. It is essential that affective objectives be identified for each learning situation and that relevant, valid and reliable instruments be designed to measure their attainment objectively. The impact of affective elements, in both the student and evaluator, in the clinical situation must however also be kept in mind.

Attention must be given to personal relationships in clinical nursing to guard against the threat of technology to humanism in nursing.

\section{INLEIDING}

Is $u$ werklik van mening dat gesindheid by enige verpleegkundige objektief geëvalueer kan word? Indien u dit wel glo, is daar seker geen plek waar hierdie evaluasie beter gedoen kan word as juis in die kliniese onderrigsituasie nie want hier word die student blootgestel aan die komplekse eise van die werklikheidsituasie. Daar word algemeen aanvaar dat leer uit drie komponente saamgestel is naamlik:

- die kognitiewe element;

- die psigo-motoriese element;

- die affektiewe element.

Die affektiewe komponent is seker die moeilikste van die drie om te evalueer aangesien dit normaalweg uiters moeilik is om mense se gevoelens en houdings akkuraat te bepaal. Dieselfde gedrag by verskillende persone het dikwels nie dieselfde affektiewe oorsprong nie; een persoon kan uit louter vreugde glimlag terwyl dit by 'n ander op verborge antipatie of verset kan dui.

Die evalueringsbeginsel as essensiële komponent van die verpleegonderwysopset verg sonder twyfel die volgehoue verbondenheid van alle professionele verpleegkundiges. Nieteenstaande hierdie feit geskied die evalueringsproses steeds in baie gevalle op ' $n$ ongestruktureerde en ongesistematiseerde wyse. Al te dikwels maak die evalueerder nie gebruik van 'n suiwer objektiewe beoordeling van die geëvalueerde nie, maar word daar teruggeval op 'n subjektiewe mening as beoordelingsmetode.

Soos reeds aangetoon, word daar in die kliniese onderrigsituasie in mindere of meerdere mate wel gebruik gemaak van 'n geordende strategie ten opsigte van die evaluering op psigomotoriese en kennisvlakke. Sodra die affektiewe aspek egter beoordeel moet word, word dikwels 'n skaal gebruik slegs in ooreenstemming met die mening en/of die subjektiewe gevoelskomponent van die evalueerder. Die vraag kan gestel word of die evalueerder in die kliniese onderrigsituasie enige ander of objektiewe metode(s) van evaluering het waarvan sy gebruik kan maak. Soos later uit hierdie aanbieding sal blyk, is die antwoord ja dog daar bestaan nog baie leemtes en ruimte vir navorsing.

Baie jare lank was die evalueringsproses die mees verwaarloosde aspek in die verpleegproses, te wyte aan die feit dat niemand werklik iets gedoen het ten opsigte van ob- jektiwiteit by beoordeling nie. In vergelyking met die evaluerings wat twee tot drie dekades gelede gedoen is, is daar reeds groot vorderıng gemaak ten opsigte van psigomotoriese en kennisvlakke. Dit is dus noodsaaklik dat daar ook indringend aandag geskenk word aan die affektiewe sy van evaluering. Dit is tog onaanvaarbaar dat die evalueerder tevrede kan wees met 'n hoogs gesofistikeerde en sogenaamd korrekte uitvoering van 'n verplegingstaak terwyl die gevoelsdimensie van die pasiënt in gebreke bly en die houding van die student teenoor die pasiënt/kliënt nie 'n integrale deel van die evalueringsproses uitmaak nie. Dit is tog werklik ondenkbaar dat die affektiewe element van die geëvalueerde in hierdie opset nie in berekening gebring word en dat sy/hy ò nie krediet kry nie of gepenaliseer word ten opsigte van haar gesindheid teenoor die belangrikste persoon in die gesondheidsdiens, te wete die pasiënt/klient.

\section{DIE KONSEP GESINDHEID}

Die gesindheidstruktuur is ' $\mathrm{n}$ omvattende begrip waarin die modaliteite van die affektiewe, kognitiewe en gedragskomponente inbegrepe is. Hierdie drie komponente is 
onderling verwant en veranderinge in 'n persoon se kennis sal noodwendig sy gevoelens en gedragsneigings verander. So kan daar byvoorbeeld van 'n studentverpleegkundige in haar derde studiejaar baie meer verwag word - nie slegs ten opsigte van haar kennis van die geneeskunde nie, maar ook ten aansien van haar gedrag en benaderingswyse teenoor die pasiënt /kliënt.

Die gesindheids- of affektiewe element van ' $n$ persoon het in hoofsaak te make met:

\section{Houding}

Dit is basies die gemoedstoestand of oortuiging van 'n persoon en dit beïnvloed andere in mindere of meerdere mate. 'n Groot probleem wat die evalueerder hier moet oorbrug, is om te bepaal of die geëvalueerde se uiterlike reaksies 'n presiese weergawe van sy werklike gevoelens is. Die evalueerder kan slegs afleidings maak uit die verbale uitdrukkings of openlike gedrag van die geëvalueerde.

\section{Waardering}

Dit is fyn en sensitiewe waarnemings van die waarde wat 'n idee of gebeurtenis vir 'n persoon het. Waarde moet hier gesien word volgens sy nut vir die verpleegkundige self of vir die beroep.

\section{Belangstelling}

Omdat belangstelling gewoonlik verborge is, is dit uiters moeilik vir die evalueerder om die vlak te bepaal waarop dit teenwoordig is wanneer ' $n$ bepaalde taak uitgevoer word. Ten spyte van die feit dat baie aktiwiteite geassosieer word met belangstelling bly die grootste probleem nog om te bepaal of 'n bepaalde optrede werklik op belangstelling dui en of die student dit bloot uitvoer ten einde dit afgehandel te kry. Belangstelling kan beskou word as in uitdrukking van begeerte en/of motiewe ten opsigte van sekere objekte of gebeurtenisse.

Die gevoelskomponent verwys na die emosies en stemminge wat die verpleegkundige ervaar en wat gekoppel word aan 'n sekere voorwerp. Dit is hierdie emosie van genot of afkeer of afsydigheid teenoor die objek wat haar gedrag en optrede bepaal. Daar moet in gedagte gehou word dat elke individu sekere oortuigings en menings het en dat dit ook in ' $n$ mindere of meerdere mate 'n uitwerking het op die gesindheid wat in die kliniese evalueringsituasie openbaar word.

Dit is so dat die mens se leefwêreld vir hom betekenis kry volgens die waarde en gevoel wat hyself daaraan toeskryf, dus sal hy altyd probeer om strydighede tussen sy gesindheid en 'n objektiewe feit rasioneel te regverdig en derhalwe steeds te glo dat sy feite korrek is.

Die affektiewe komponente is die belangrikste faktor in die gesindheidstruktuur. Die feit dat dit kenmerkend is dat ' $n$ gevoelsreaksie baie gou aangeleer en dikwels reeds jare lank aanwesig is, maar baie moeilik en stadig gewysig kan word, moet altyd by evaluering in die kliniese situasie voor oë gehou word.

\section{DIE EVALUERINGSMILIEU}

Kliniese onderrig is die belangrikste metode van onderrig in die verpleegopset. Daar kan dus tereg gekonstateer word dat die dienseenhede, hetsy binne of buite inrigtings, die voedingsbodem vir kliniese evaluering vorm. Hier het die verpleegkundestudent met die werklikheid te make en dit kan tereg die laboratorium van die verpleegkunde genoem word. Om een of ander rede skram baie verpleegopvoeders heel onwetenskaplik van hierdie ryk en vrugbare opvoedingsterrein weg. Waarom? Is dit moontlik dat hierdie opvoeders nie die vaardigheid en kundigheid het nie, wat moontlik te wyte is aan onvoldoende/foutiewe opleiding, of dat hulle dit weer verloor het sodat hulle hierdie terrein nie werklik kan benut nie? Bewyse word algemeen gevind dat die mens hom distansieer van betrokkenheid. Is dit moontlik ook in ons beroep van toepassing? Indien dit wel te wyte is aan die feit dat ontvlugting uit hierdie realiteit gesoek word, dan is dit heelwaarskynlik ook so dat hulle gesindheid teenoor die kliniese veld en diegene wat hulself steeds in die kliniese veld bevind, veel te wense oorlaat. 'n Verdere vraag ontstaan dan: indien die houding van die opvoeders nie na wense is nie, hoe word die student beïnvloed en met watter ingesteldheid word sy geëvalueer?

Dit is juis in die kliniese veld dat die verpleegstudent haarself as skeppende beroepsmens en doelgerigte deelnemer aan die gesondheidstaak kan bewys. Die skepping van 'n omgewing vir optimale beroepsgroei en wat gelyktydig die gevoelsdimensie van die siek persoon in aanmerking neem, is die gesamentlike verantwoordelikheid van verpleegadministrateurs en opvoeders

Hoe kan die regte agtergrond vir die evalueringstoneel geskep word? Deur:

- benutting van die administratiewe proses as grondslag vir die opvoedkunde;

- aktiewe deelname van die pasiënte. Hulle is immers die essensiële komponent van die leerstof en die leerervaring van die studente wat geëvalueer moet word;

- insae deur die geëvalueerde oor aanvaarbare en gewenste gedrag op die affektiewe vlak;

- die voortdurende inskerping van die betrokkenheid van een mens by 'n ander;

- kennis en kundigheid van die personeel wat voortdurend versterk moet word deur personeelontwikkeling:

- skriftelike kriteria en doelstellings vir alle betrokkenes:

- erkenning van die andersheid van die formele situasie in teenstelling met die volgehoue informele situasie waar groepsgenote of die persoon self of ander personeel in die dienseenheid hoofsaaklik die evaluering doen;

- handhawing van in normale saalklimaat om spanning te verminder.

Die geëvalueerde moet dus op haar gemak voel, sy moet weet presies wat daar van haar op die gevoelsvlak verwag word, en die omgewing waarin die evaluering plaasvind moet optimaal gereed wees vir die evalueringsproses. Onder sulke omstandighede kan die geëvalueerde haar beste lewer en is die evalueerder in staat om met die metodes tot haar beskikking die gel- 
digste. en betroubaarste meting te doen.

\section{GESINDHEID SOOS DIT VER- BAND HOU MET DIE DIDAK- TIESE OPSET}

Wie van ons het nog nie die twyfelagtige voorreg gehad om in die skoene van die geëvalueerde te staan nie?

Die gedrag en gesindheid wat die geëvalueerde in die kliniese onderrigsituasie openbaar, word noodwendig beïnvloed deur verskillende faktore waaronder die volgende van die belangrikste is:

- angs en vrees beinvloed die denke, houdings en optrede van sommige mense baie meer as dié van ander;

- handvaardigheid en hand- en oogkoőrdinasie speel 'n baie groot rol in die gemak en vaardigheid waarmee 'n individu 'n bepaalde taak kan afhandel;

- positiewe of negatiewe valensie wat die leerstof en evalueerder vir die geëvalueerde het;

- individuele verskille ten opsigte van persoonlikheid, byvoorbeeld vriendelikheid teenoor stugheid; introversie versus ekstroversie;

- kennis en intellektuele vermoë waaroor die geëvalueerde beskik;

- die selektiewe belang wat elke mens het en dus ook die verpleegkundestudent;

- stadium van opleiding en mate van bemeestering en vlotheid waarmee take uitgevoer word;

- motivering ten opsigte van dienslewering aan die gemeenskap en in besonder aan die siek persoon;

- die mate van kennis ten opsigte van die kriteria vir beoordeling waarvan die evalueerder gebruik gaan maak.

Selfversekerheid by die geëvalueerde spruit dikwels uit die wete dat sy oor die kennis en vaardigheid beskik om 'n bepaalde taak aan te pak en deur te voer en dit tel beslis in haar guns by evaluering. Hierdie selfversekerdheid word gewoonlik nie oornag verkry nie, maar deur oefening en herhaling bemeester. In hierdie verband speel prys en beloning deur senior verpleegpersoneel 'n groot rol om die jong stu- dent 'n gevoel van eiewaarde en trots te laat opbou. Opbouende kritiek in 'n aangename atmosfeer spcor haar aan tot verbetering van vorige foute en het baie groter waarde as 'n onbuigsame houding en dissiplinering.

\section{Die evalueerder}

Dit is 'n onomstootlike feit dat die gedrag van die geëvalueerde nie noodwendig presies dieselfde betekenis vir die evalueerder of toeskouer het as wat dit vir eersgenoemde het nie. Tensy 'n suiwer objektiewe en voorafbeplande meetinstrument gebruik word, word die evaluering van 'n student gewoonlik baseer op die gesindheid van die evalueerder.

Die evalueerder moet verder onthou dat kulturele faktore en verskillende en uiteenlopende lewensgewoontes en gebruike soos dit in die Westerse wêreld weerspieël word, die grondslag van die waarde-oordele van die mens vorm en dit normatief reguleer. Selfs by verskillende evalueerders is daar ' $n$ diversiteit van kulturele beslag, en desnieteenstaande word daar 'n onbevooroordeelde en objektiewe uitvoering verwag. 'n Mens moet jou noodwendig met hiedie faktore in gedagte by Reilly skaar wanneer sy sê dat evaluering nie objektief kan wees nie - dit kan regverdig wees.

Die vrae ontstaan onwillekeurig: is dit die evalueerder se erns en besef sy ten volle die belangrikheid van die taak wat sy vervul en die rol wat sy daarin speel? Is sy bewus van die negatiewe gevoelens en vrees waarmee die geëvalueerde die situasie benader? Dit is dus die plig van die evalueerder om allereers daartoe oor te gaan om hierdie muur tussen hulle af te breek en 'n positiewe gesindheid by die geëvalueerde teweeg te bring. Daarna het sy verder die taak om so 'n gesindheid te openbaar dat die student tot volwassenheid en volwaardigheid in die beroep kan gedy. Dit kan slegs geskied indien die evalueerder liefde uitstraal - liefde en begrip vir haar medemens, liefde en respek vir die verplegingsberoep en verder lojaliteit teenoor haar werkgewer. Sodanige gesindheid moet noodwendig 'n positiewe uitwer- king op die geëvalueerde hê. Die evalueerder moet haarself voortdurend afvra of sy toegelaat het dat haar eie persoonlike gevoelens jeens die geëvalueerde haar oordeel oor die student se houding beïnvloed het. Waar dit gaan oor die evaluering van houdings en gesindhede van ander is selfevaluasie van besondere belang.

\section{METODIEKE VIR GESIND- HEIDSEVALUERING}

The critical issue in determining the method to use, is knowing what is to be evaluated. (Tobin et al 14, p. 168)

Dit is dus noodsaaklik om spesifieke affektiewe gedragsdoelwitte vir 'n bepaalde leerervaring te identifiseer alvorens daar tot die bepaling van 'n metode vir gesindheidsevaluering oorgegaan kan word. Daarom is dit belangrik dat hiedie doelwitte evalueerbaar moet wees.

Verskeie outoriteite bied 'n taksonomie of klassifikasie hiervoor aan. Alhoewel meting van die gevoelsdimensie die moeilikste is, kan skale opgestel word om studentaktiwiteite, reaksies en houdings te probeer evalueer.

Die volgende skaal word deur Guilbert by wyse van die vertrouensverhouding, as voorbeeld aangedui:

Die student het alle nodige voorsorgmaatreëls getref en die pasiënt lyk heeltemal ontspanne

Die student het die nodige voorsorgmaatreëls getref en het op verskeie geleenthede die pasiënt se vertroue versterk

Die student het 'n poging in hierdie rigting aangewend en kennis geneem van die resultaat ........ 3

Die student het 'n poging aangewend sonder om te probeer bepaal wat die resultaat was

Die student lyk nie asof sy eers die probleem opgemerk (raakgesien) het nie

Beoordelingskale moet volgens opvoedkundige doelwitte opgestel word en dit moet betrekking hê op die houding wat as gunstig beskou word vir die bepaalde taak wat 
verrig word. Die formulering van hierdie doelwitte mag nooit so wees dat dit die bevrediging van die pasiënt/kliënt se behoeftes op psigososiale vlak buite rekening laat nie. Per slot van sake is die pasiënt/kliënt self 'n evalueerder en is hy gewoonlik die een wat onderworpe is aan die prosedure wat geëvalueer moet word.

Sommige opleidingskole is reeds betrokke by kriteriumgerigte praktika waarin die kognitiewe, psigomotoriese en affektiewe vlakke eweredig verswaring kry. Die formulering van sodanige doelwitte en kriteria is ' $n$ veeleisende en omvangryke taak waarvoor die vindingrykheid en motivering van die gesofistikeerde verpleegopvoeder inderdaad nodig is. Dit is verreweg nie 'n eemanstaak nie en spesialiteitskennis soos deur die veelfasettigheid van die beroep verteenwoordig, is hiervoor nodig.

In sekere Kaapse provinsiale hospitale word 'n puntskaal gebruik by die beoordeling van kennis, bevoegdheid en ook houding in kliniese onderrig.

Die uitvoer van 'n eenvoudige steriele prosedure kan as voorbeeld geneem word:

1. Die doel waarom die prosedure gedoen word, word bepaal.

2. Die doelstellings vir bevoegdheid waaroor die student moet beskik vir die prosedure, word aangedui.

3. Sekere kritiese faktore wat beoordeel moet word, word uitgelig bv:

Voorbereiding (wat die belangrikste faktore wat geëvalueer moet word ten opsigte van voorbereiding insluit, bv verbandkamer, uitset van trollie, die verpleegkundige)

Uitvoer van die prosedure (met 'n uiteensetting van die belangrikste faktore wat geëvalueer moet word ten opsigte van die uitvoer van die prosedure)

Afronding (met 'n uiteensetting van die belangrikste faktore wat geëvalueer moet word ten opsigte van die uitvoer van die pro- sedure)

4. Evaluering van kennis ten opsigte van bogenoemde kritiese faktore op 'n 5-puntskaal.

5. Evaluering van bevoegdheid ten opsigte van bogenoemde kritiese faktore op 'n 5-puntskaal.

6. Evaluering van houding ten opsigte van bogenoemde kritiese faktore op 'n 5-puntskaal.

Die skaal wissel van: 1 - besit nog nie die basiese vaardighede nie tot 5 - heeltemal bevoeg

\section{GESINDHEIDSEVALUERING AS KONTEMPORÊRE VRAAGSTUK VIR VERPLEEG- ONDERWYS}

Die kliniese beroepsveld is en bly die teiken van die verpleegdiens. Dit is die plek waar ons konsulteer en konfronteer met die doel om te koördineer en te beheer. Dit alles gaan om verbetering van die diens wat gelewer moet word in 'n era van soveel kennis, soveel tegnologiese verandering en die steeds toenemende eise wat die verbruiker stel.

'n Mens kan die taak van die verpleegopvoeder sien as een van die grootste uitdagings van die verpleegberoep, want dit wat ons akademies of teoreties verkondig, moet noodwendig tot op die kliniese evalueringsvlak deurdring. Al te dikwels word daar uitlatings gemaak oor die sogenaamde tegnologie wat 'n bedreiging inhou vir die humanisme in ons beroep. Ten einde hierdie situasie die hoof te bied, is dit noodsaaklik dat daar voortdurend en intensief aandag gegee moet word aan die interpersoonlike verhoudings wat tydens kliniese verpleging gehandhaaf word.

Dit is 'n veld wat nog braak lê vir verpleegnavorsing - 'n veld waaraan verpleegkundiges hul daadwerklik kan toewy ten einde die einddoel van affektiewe objektiwiteit, onbevooroordeelde evaluering en die uitskakeling van subjektiewe waarde-oordele te verwesenlik.

\section{SLOT}

Ten slotte kan die uitwerking van en die ontsettende rol wat die affektiewe element by beide die evalueerder en die geëvalueerde in kliniese onderrig speel, nie oorbeklemtoon word nie. In hierdie verband moet die pasiënt se emosionele ervarings, afkomstig uit hierdie gevoelsdimensie, ook in berekening gebring word en moet die groot betekenis van die houdings en verhoudings van gesondheidswerkers teenoor hul kliënte, nie onderskat word nie.

Die verpleegopvoeder sal dit vir haarself ten doel moet stel om die humanistiese benadering verder te voer as ' $n$ mooi en benydenswaardige ideaal, maar sal alles in die stryd moet werp om die affektiewe opset van dienslewering te kwantifiseer. Daar sal aanvaarbare kriteria opgestel moet word wat deur voortgesette onderwys verstrek behoort te word.

Herhaalde bepalings van gehalte, versekering van die sisteem, hetsy in die vorm van die verpleegproses self, die verpleegoudit of probleemgerigte rekords is 'n essensiële taak waarmee die verpleegleiers van vandag verplig is om hulself te bemoei. Dit is noodsaaklik dat die stelsel, die student en die evalueringsituasie so na as moontlik aan die totaliteitsbehoeftes van die verbruiker gebring moet word.

Die sleutel tot sukses lê in die opstel van 'n bruikbare, praktiese meetinstrument wat geldig, betroubaar, objektief en relevant moet wees.

\section{BRONNELYS}

\footnotetext{
1. Guilberr. J.J. Educarional Handbnok for health person nel. W.H. Geneva 1977

2. Kemp. P. B. Die houding leenoor onderwys as beroep 3. Kemp. B. P. Gesindhede by kandidaatonderwysers in lig gaamlike opvoeding - in psigo-pedagogiese studie.

4. Nunnaly, J.C. Educational measurement and evaluation Second edition. McGraw-Hill 1972.

5. Perry. E.L. Ward Management and Teaching Second edition. Bailliêre Tindall. London. 1978

6. Reilly, D.E. Behavioural Objectives in Nursing - Evalu arion of learner atrainment. Second edition. AppletonCentury-Crofts. 1975

7. Snelbecker. G.E. Learning theory, instructional theory and psycho-educational design McGraw.Hill. New York. 1974

8. Tobin. H.M. et al. The process of staff deveiopment com ponents for change C.V. Moshy Si Lowis 1979. 2nd Ed

9. Yura, H \& Walsh. M. The nursing prucess AppletionCentury-Crofts. New York. 1978. 3rd Ed
} 